\title{
Hepatitis B immunization strategies: timing is everything
}

\author{
Christopher O. Mackie MD MHSc, Jane A. Buxton MBBS MHSc, Sayali Tadwalkar MD BHSc, \\ David M. Patrick MD MHSc
}

$\mathrm{S}$ ince the launch of the first universal vaccination program against hepatitis B virus (HBV) in Taiwan in 1984, there has been ongoing research and debate about the most appropriate vaccination schedule. Vaccine advisory bodies continue to examine universal immunization strategies to determine which are most appropriate to protect against $\mathrm{HBV} \cdot{ }^{1,2}$ In this article, we review the evidence for long-term effectiveness of vaccination programs for infants and adolescents. The search strategy used is available in Appendix 1 (available online at www.cmaj.ca/cgi/content /full/180/2/196/DC1).

Chronic HBV infection, with the attendant risk of cirrhosis and hepatocellular carcinoma, occurs in 1\%-5\% of adults and up to $90 \%$ of infants who are infected with HBV..$^{3-5}$ Providing vaccinations during adolescence without offering vaccinations during infancy misses this critical period when the acquisition of a HBV infection can be the most harmful. Epidemiologic studies show that the age distribution of HBV varies by jurisdiction and suggest that roughly one-third of chronic infections are acquired during infancy and early childhood. ${ }^{6-9}$ An ideal vaccine schedule should protect against infection both in infancy, when the risk of becoming a chronic HBV carrier is highest, and in adolescence, when high-risk sexual and drugusing behaviours occur more frequently.

Epidemiologic data are critical for informing decisions about vaccination. Estimating the age-specific incidence of acute infections is valuable for planning prevention measures. However, acute infections in infants and toddlers may be missed because HBV infection is often asymptomatic in young children. In many jurisdictions, the age-specific incidence of $\mathrm{HBV}$ infection is unknown.

The controversy surrounding booster injections stems in part from the rapid drop in antibodies after completion of the primary series of injections. Serum levels of antibodies against hepatitis B surface antigen have been used to measure the initial response to vaccination (antibody levels $\geq 10 \mathrm{IU} / \mathrm{L}$ are considered protective). This marker measures response to the vaccine within the first few weeks but is not an appropriate indicator of long-term immunity. Serologic studies have shown that the titre of antibodies against hepatitis B surface antigen drops within the first few years after vaccination and that one-third to one-half of children vaccinated as infants will have titres below 10 IU/L by $10-15$ years of age. ${ }^{10-12}$ This has been misinterpreted to mean that population-level protection shows a similar dramatic drop.

\section{Key points}

- All countries should offer universal HBV vaccination for infants.

- Targeting universal immunization programs at infants helps to maximize population-level protection.

- Booster doses for healthy adolescents who were immunized as infants are not necessary.

- Universal immunization in adolescents can reduce the burden of HBV-related illness in adolescents.

- Adequate data are needed to evaluate immunization programs.

- A national immunization registry is a key component of any evaluation strategy.

Long-term observational data show that vaccinated individuals - even those who have an undetectable titre of hepatitis B surface antigen - can mount an anamnestic response to contact with HBV..$^{11,13}$ A recent booster trial performed 18 years after vaccination of infants in Gambia provides further evidence of persistent immunity. ${ }^{14}$ Although almost $70 \%$ of participants had no detectable antibodies at baseline, of the 181 participants who were tested 2 weeks after receiving a booster dose, $92.3 \%$ (95\% CI 87.4-95.7) showed an early anamnestic response. ${ }^{14}$ The geometric mean concentration of antibodies against hepatitis B surface antigen in this group rose to $524 \mathrm{IU} / \mathrm{L}$ (95\% CI 441-621), which suggests that most people who have been vaccinated can mount a protective immune response even 18 years after receiving a primary series of vaccinations in infancy.

\section{Universal vaccination of infants}

As of 2007, 171 of the 193 member countries of the World Health Organization (WHO) had implemented the recommendations of the Expanded Programme on Immunization to offer universal hepatitis B vaccination to infants. ${ }^{15}$ Observational evidence suggesting that vaccination of infants against HBV offers long-term protection is abundant. Serologic surveys provide evidence that the incidence and prevalence are dramatically reduced in populations that have universal vacci-

From the Department of Clinical Epidemiology and Biostatistics (Mackie), McMaster University; Public Health Services (Mackie), City of Hamilton, Hamilton, Ont.; the Department of Epidemiology (Buxton, Patrick), BC Centre for Disease Control; and the School of Population and Public Health (Buxton, Tadwalkar), University of British Columbia, Vancouver, BC 
nation of infants. Several studies have shown that in the first decade of life, acute infections are uncommon, and chronic infections are rare in populations in which infants are vaccinated. ${ }^{16-18}$ Even in groups at high risk of HBV infection, low rates of infection have been achieved up to 18 years after vaccination. ${ }^{11,13,19}$ These data, which suggest that vaccination of infants can offer excellent protection into adolescence, are summarized in Table 1.

When compared with the incidence and prevalence in historical control groups, the incidence and prevalence of HBV infection has declined dramatically in several jurisdictions (Table 1). However, without a contemporaneous control group, it may not be possible to attribute the documented decline solely to immunization programs. Improvements in hygiene practices in hospitals and the community may be responsible for part of the decline in the incidence of HBV infection, which would cause vaccine effectiveness to be overestimated. Loss to follow-up in long-term studies may also introduce bias. In the case of HBV, where loss to follow-up may be related to important factors such as high-risk sexual behaviour and drug use, vaccine effectiveness may be further overestimated.

Data are available to compare vaccinated individuals with contemporaneous unvaccinated controls. Related in part to ethical concerns about withholding a proven vaccine, there are few long-term studies of HBV that have included unvaccinated individuals. However, there are now 3 such studies, including a randomized controlled trial. ${ }^{10,12,14}$ Two separate observational studies from Gambia and a study from China involving children who had been vaccinated as infants estimated vaccine effectiveness against chronic infection to be $89 \%-96 \%$ in children aged 10-15 years (Table 2). ${ }^{10,12,14}$ The Gambian studies were made possible in part by Gambia's national immunization registry. Selection bias in the Gambian studies and loss to follow-up in the Chinese study may have lead to an overestimation of effectiveness, although the researchers in each study took steps to minimize these factors.

Table 1: Long-term (> $10 \mathrm{yr}$ ) studies (without control groups) of HBV vaccination in infants

\begin{tabular}{|c|c|c|c|c|c|c|}
\hline Jurisdiction & $\begin{array}{c}\text { Age at } \\
\text { follow-up, } \\
\text { yr }\end{array}$ & $\begin{array}{c}n \\
(n \text { at } \\
\text { follow-up) }\end{array}$ & $\begin{array}{l}\text { No. of cases } \\
\text { of HBV } \\
\text { infection* }\end{array}$ & $\begin{array}{l}\text { No. }(\%) \text { of cases } \\
\text { of chronic HBV } \\
\text { infectiont }\end{array}$ & $\begin{array}{l}\text { Baseline prevalence } \\
\text { of hepatitis B } \\
\text { surface antigen }\end{array}$ & Study design and comments \\
\hline Alaska" & $12-16$ & 338 (99) & 6 & $0(0 \%)$ & $6 \%-14 \%{ }^{20,21}$ & $\begin{array}{l}\text { Prospective cohort; serial serology; } \\
4 \text { anamnestic responses documented }\end{array}$ \\
\hline Taiwan $^{19}$ & 18 & 670 (NA) & 35 & $13(1.9 \%)$ & $15 \%-20 \% \%^{22,23}$ & $\begin{array}{l}\text { Cross-sectional serological survey of } \\
\text { all university entrants }\end{array}$ \\
\hline Hong Kong ${ }^{13}$ & 18 & $318(88)$ & 3 & $0(0 \%)$ & $10 \%{ }^{24}$ & $\begin{array}{l}\text { Randomized controlled trial with all } \\
\text { arms receiving the vaccine; serial } \\
\text { serology; } 88 \text { anamnestic responses } \\
\text { documented }\end{array}$ \\
\hline
\end{tabular}

Note: NA = not appropriate for study design.

*Defined as the presence of antibodies against the hepatitis B core antigen.

tDefined as the presence of hepatitis B surface antigen.

Table 2: Long-term (> $10 \mathrm{yr}$ ) studies with control groups of HBV vaccination in infants

\begin{tabular}{|c|c|c|c|c|c|}
\hline \multirow[b]{2}{*}{ Jurisdiction } & \multirow{2}{*}{\multicolumn{2}{|c|}{$\begin{array}{c}\text { Age at } \\
\text { follow-up, yr ( } n \text { at follow-up) }\end{array}$}} & \multicolumn{2}{|c|}{ Vaccine efficacy } & \multirow[b]{2}{*}{ Study design and comments } \\
\hline & & & $\begin{array}{l}\text { Against any HBV } \\
\text { infection* }\end{array}$ & $\begin{array}{l}\text { Against chronic } \\
\text { infectiont }\end{array}$ & \\
\hline \multirow[t]{3}{*}{ Gambia $^{10}$} & $10-14$ & 411 (NA) & $82 \%$ & $96 \%$ & Cross-sectional serological survey \\
\hline & \multirow[t]{2}{*}{$>15 \ddagger$} & \multirow[t]{2}{*}{$171 \mp(\mathrm{NA})$} & $(95 \% \mathrm{Cl} 75 \%-87 \%)$ & $(95 \%$ Cl 82\%-99\%) & comparing vaccinated and unvaccinated \\
\hline & & & $\begin{array}{c}65 \% * \\
(95 \% \mathrm{Cl} 56 \%-73 \%)\end{array}$ & $\begin{array}{c}88 \% * \\
(95 \% \mathrm{Cl} 68 \%-95 \%)\end{array}$ & $\begin{array}{l}\text { children } \\
\text { Sampling performed in a population } \\
\text { where a randomized controlled trial had } \\
\text { been conducted }\end{array}$ \\
\hline China $^{12}$ & 15 & 649 (106) & $\begin{array}{c}86 \% \\
(95 \% \text { Cl } 71 \%-100 \%)\end{array}$ & $\begin{array}{c}89 \% \\
(95 \% \text { Cl } 60 \%-100 \%)\end{array}$ & $\begin{array}{l}\text { Randomized controlled trial with placebo } \\
\text { group }\end{array}$ \\
\hline Gambia $^{14}$ & 15 & 916 (NA) & $\begin{array}{c}67 \% \\
(95 \% \mathrm{Cl} 58 \%-75 \%)\end{array}$ & $\begin{array}{c}97 \% \\
(95 \% \text { Cl } 92 \%-100 \%)\end{array}$ & $\begin{array}{l}\text { Cross-sectional serological survey } \\
\text { comparing vaccinated and unvaccinated } \\
\text { children }\end{array}$ \\
\hline
\end{tabular}

Note: $\mathrm{NA}=$ not appropriate for study design, $\mathrm{Cl}=$ confidence interval.

*Defined as the presence of antibodies against the hepatitis B core antigen.

tDefined as the presence of hepatitis B surface antigen.

\#These children were vaccinated at age 1-4 years with nonstandard regimens that are not currently in use. Comparison of this group with the 10-14 year old cohort in the same study is not appropriate. 
There are 2 major challenges to universal vaccination programs for infants. The first challenge is that vaccination against HBV before 1 year of age is more effective than after. This was identified in the first vaccine trial in an area where HBV is endemic. In Senegal, children up to 2 years of age were vaccinated and followed for 9-12 years. ${ }^{25}$ This study reported good protection among those who had been vaccinated compared with those who had not, ${ }^{25}$ but this trial failed to achieve the level of protection achieved in other studies. ${ }^{11,13,19}$ The authors attributed this to the later age at which vaccination occurred in their cohort and recommended that vaccination occur as early as possible. A similar study in New Caledonia confirmed this finding. ${ }^{26}$ At 10 years of age, children whose HBV vaccination series began before 1 year of age were well protected. ${ }^{26}$ This study reported that $4.3 \%$ of children were positive for antibodies to hepatitis B core antigen, which is a marker of past infection. Among those who began to receive vaccinations between 1 and 2 years of age, $21.4 \%$ were positive for antibodies to hepatitis $\mathrm{B}$ core antigen. ${ }^{26}$

The second challenge is that hepatitis $\mathrm{B}$ vaccines become unstable with even a single exposure to temperatures below $0.5^{\circ} \mathrm{C}$. Researchers in Mongolia identified that children there did not benefit as dramatically as those in other countries ${ }^{27}$ and that rural children were particularly affected. ${ }^{28}$ They suspected that the cold winters and the resource challenges faced in rural clinics played a role. This was confirmed when they showed that children who received all 3 doses in the winter had almost no protection against HBV infection. ${ }^{29}$ The experiences in Mongolia, Senegal and New Caledonia highlight the need for each jurisdiction to conduct ongoing evaluation of immunization programs and surveillance for vaccine preventable diseases.

\section{Universal vaccination of adolescents}

Three countries and some Canadian provinces (Alberta, Saskatchewan, Manitoba, Ontario, Quebec, Nova Scotia and Newfoundland and Labrador) offer universal vaccination of adolescents or preadolescents instead of infants. ${ }^{30,31}$ Observational studies in British Columbia, Quebec and Catalonia, Spain, suggest that universal vaccination of preadolescent or adolescent children reduces the incidence of HBV during adolescence. ${ }^{1,32,33}$ Similar to the results from studies of programs involving infants, these results may have been affected by changes in hygiene practices in hospitals and in the community, which may have lead to an overestimation of the effectiveness of the immunization programs. Authors of the Spanish study suggest that improved reporting may have lead to an underestimation of vaccine effectiveness in their jurisdiction, and the Canadian authors state that reporting did not change significantly over the course of their studies. ${ }^{1,32,33}$ Table 3 summarizes the results of long-term studies in adolescents.

With its large size, jurisdictional diversity and strong reporting systems, Canada provides a natural experiment in HBV immunization. Most Canadian provinces implemented universal HBV vaccination for adolescents in the early to mid 1990s. In 2001, British Columbia became the only province to offer universal vaccination to both adolescents and infants. Since the implementation of the infant vaccination program, the reported incidence of acute HBV infections has continued to decline in British Columbia, while it has levelled off in other provinces and in Canada as a whole (Figure 1). After years of having a higher incidence of HBV infections than other provinces, British Columbia now has an annual incidence that is consistently below the national average.

British Columbia has had only 2 reported cases of acute HBV infection since the implementation of its universal infant immunization program. Zero cases have been reported in the past 4 years (British Columbia Integrated Public Health Information System). Reported rates of acute infections in infants have remained relatively stable or increased since 2007 in other provinces and in Canada as a whole (Figure 2). Researchers in Quebec have observed the persistence of infections in infants and young children in spite of decreasing rates in the general population, and they are now calling for a universal vaccination program for infants in that province.'

Underreporting of HBV infections, particularly among infants, limits the value of ecological level data. In Canada, 2 additional factors that influence underreporting should be considered. First, case definitions, which are now standardized nationally, varied slightly between jurisdictions over time. Direct comparisons of rates between provinces may be

Table 3: Long-term studies with historical control groups of HBV immunization in adolescents

\begin{tabular}{|c|c|c|c|c|c|}
\hline Jurisdiction & $\begin{array}{c}\text { Age at } \\
\text { vaccination, yr }\end{array}$ & $\begin{array}{c}\text { Study period, } \\
\text { no. of } y r\end{array}$ & $\begin{array}{l}\% \text { of adolescents } \\
\text { vaccinated }\end{array}$ & $\begin{array}{l}\text { Change in reported annual } \\
\text { incidence of acute HBV, } \\
\text { per } 100000 \text { adolescents }\end{array}$ & Comments \\
\hline $\begin{array}{l}\text { British } \\
\text { Columbia }\end{array}$ & $\begin{array}{l}10 \text { or } 11 \\
\text { (grade } 6)\end{array}$ & 10 & $90-93$ & From 1.7 to 0 & $\begin{array}{l}\text { A decrease in incidence also } \\
\text { occurred in the unvaccinated } \\
\text { population }\end{array}$ \\
\hline Quebec $^{1}$ & $\begin{array}{l}8 \text { or } 9 \\
\text { (grade } 4)\end{array}$ & 10 & $85-95$ & From 3.2 to 0.3 & $\begin{array}{l}\text { A decrease in incidence occurred } \\
\text { among unvaccinated adults but not } \\
\text { infants }\end{array}$ \\
\hline Catalonia $^{33}$ & 12 & 12 & $80-90$ & From 5.0 to 1.2 & $\begin{array}{l}\text { Positive reactions to antibodies } \\
\text { against hepatitis B core antigen } \\
\text { decreased from } 9.3 \% \text { to } 0.9 \%\end{array}$ \\
\hline
\end{tabular}


problematic, although comparisons of trends should be more robust. Second, immigration patterns differ across the country and likely impact infection rates. Improved access to universal immunization programs for infants in many Asian countries may have preferentially reduced the incidence of $\mathrm{HBV}$ infections in British Columbia, which has a disproportionate number of immigrants from Asia compared with the rest of Canada. ${ }^{37}$ Data from passive reporting systems in Spain and Canada suggest that as HBV rates drop in countries where universal vaccination is offered, immigration is becoming a more important factor in incidence and prevalence. ${ }^{1,33}$

Many jurisdictions where universal HBV vaccination is offered to adolescents, including some Canadian provinces, also target infants born to mothers positive for HBV. A Cochrane meta-analysis reported that hepatitis B immune globulin given immediately after birth, in addition to an early vaccine series, can dramatically reduce the risk of vertical transmission. ${ }^{38}$ However, cases of HBV in infants continue to occur in these jurisdictions in spite of such programs. Many of these cases may be preventable with universal vaccination of infants.

Canada has an annual birth cohort of $350000,{ }^{39}$ and it has a reported annual incidence of acute infections in infants of 1.26 per 100000 (Figure 2) that is certainly an underestimate of the true incidence. This suggests that shifting resources for $\mathrm{HBV}$ vaccination from programs for adolescents to those for infants could prevent at least 4 to 5 cases in infants at high risk of infection each year. This would likely prevent many more undiagnosed cases among infants and dozens of acute cases in young children.

The longitudinal studies described in Table 3 suggest that vaccination of adolescents against HBV offers effective, lasting protection. ${ }^{1,32,33} \mathrm{Al}-$ though some infants will likely be protected because the prevalence of HBV infection is reduced among mothers who had been vaccinated as adolescents, the persistence of new cases in infants indicates an important limitation of this approach. This persistent burden of illness in infants, combined with the evidence

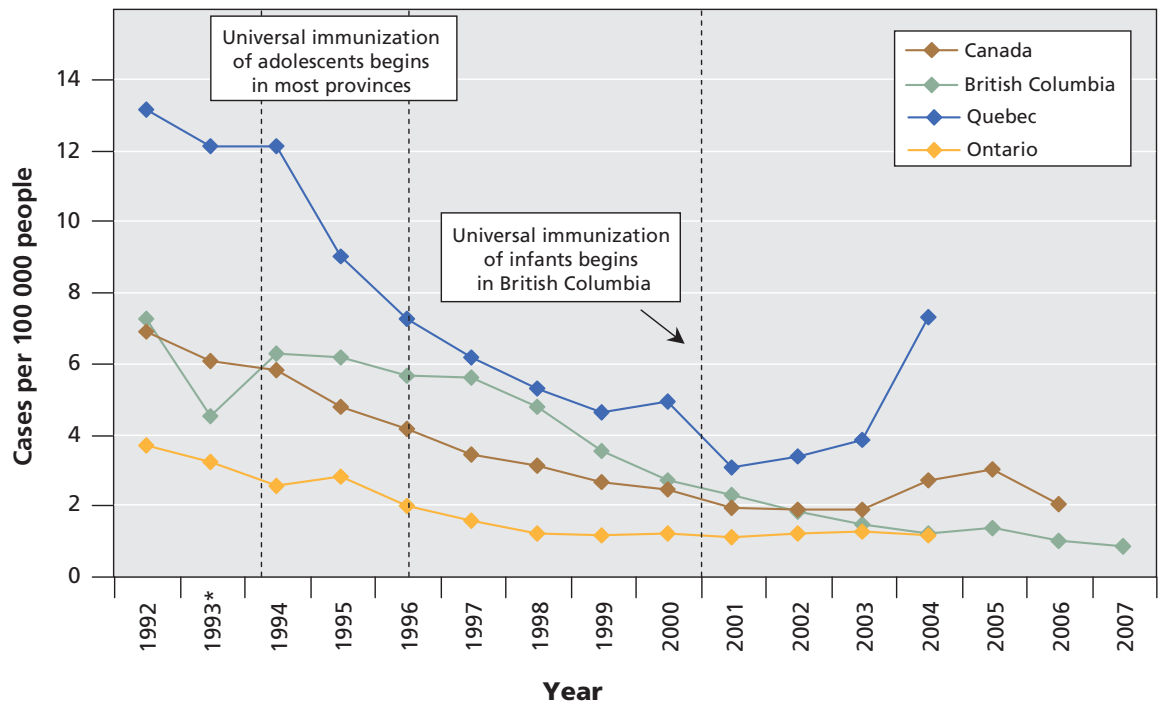

Figure 1: Reported incidence of acute hepatitis B infections among people of all ages in Canada, 1992-2007. Data were compiled from the 2007 annual report of the BC Centre for Disease Control ${ }^{34}$ and the 2005 release of the Canadian Notifiable Diseases reporting system. ${ }^{35}$ *There was a change in the electronic surveillance system in British Columbia in 1993 that resulted in some underreporting that year. ${ }^{32}$

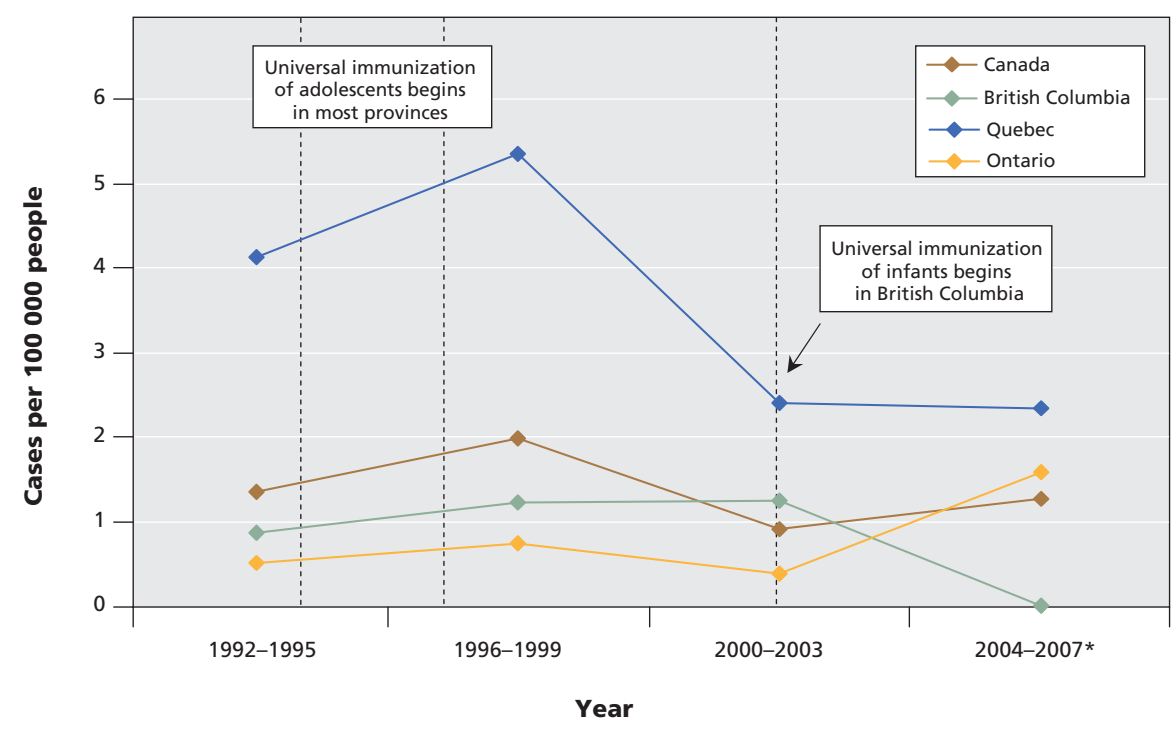

Figure 2: Reported incidence of acute hepatitis B infections among infants in Canada, 1992-2007. Data were compiled from the 2007 annual report of the BC Centre for Disease Control, ${ }^{34}$ the 2005 release of the Canadian Notifiable Diseases reporting system, ${ }^{35}$ the British Columbia Integrated Public Health Information System (iPHIS), and the Rapport sur l'ensemble des maladies des dix dernières années, Province du Quebec. ${ }^{36}{ }^{*}$ Rates for this period in British Columbia and Quebec are based on complete data from 2004-2007, while rates in Ontario and Canada are based on 2004 data. Note: Infant infections tend to be asymptomatic, and are thus underreported. Data are presented here in 4-year intervals because of the instability of small numbers.

that an infant vaccination series provides long-term protection, suggests that universal vaccination of infants is a superior alternative. 
Although the study by Lu and colleagues ${ }^{45}$ may be important from a clinical perspective in informing the timing of booster doses for high-risk individuals, this study is insufficient to guide universal immunization policy for several reasons. First, this study showed that a large portion of people who had been vaccinated had no measurable cellular or humoral response to a booster dose. This means that a subgroup of people may need a repeat series of vaccinations rather than just a booster dose and even that may not generate adequate immunity. Second, herd immunity may protect most of these people even if their own immunity wanes. Third, the rate of conversion to chronic HBV infection in those who are acutely infected as adolescents or adults is considerably lower than for those infected as infants. With the 2-dose vaccination series for adolescents costing roughly the same amount as the series for infants ${ }^{46}$ and the uncertain benefits for, at most, a few of those vaccinated, booster programs appear to be unwarranted.

\section{Moving forward}

Universal HBV immunization programs for both infants and adolescents are associated with dramatic declines in the incidence and prevalence of HBV infections in the target groups. The evidence does not support the need for booster doses later in life. The epidemiology of hepatitis B in a globalized world, where migration drives incidence and prevalence, suggests that jurisdictions should support each other by offering universal vaccination for infants.

The available evidence about duration of protection supports the recommendation by the WHO Expanded Programme on Immunization that all countries should offer 3 doses of HBV vaccine during infancy. ${ }^{15}$ Based on the Erickson and De Wals criteria, ${ }^{44}$ this approach measures up as well or better than the alternative of vaccinating adolescents (Table 4). Vaccination programs for infants may also have major cost advantages. With the availability of polyvalent vaccines that include hepatitis B vaccine along with other vaccines, programs for infants have become simple to administer. Although the cost of polyvalent vaccines is comparable to other formulations, ${ }^{46}$ program costs for vaccinating adolescents are potentially much greater because of the need for additional contact with the health care system.

The decision to choose to vaccinate adolescents in Canada appears to have been based largely on the epidemiology of acute HBV infections. ${ }^{47}$ Although the epidemiology of acute cases is important for planning interventions to prevent $\mathrm{HBV}$ infections, it would systematically bias prevention efforts toward older age groups as the rate of symptomatic infections increases. In jurisdictions that have implemented universal HBV vaccination for adolescents, the persistence of a large burden of illness among infants should serve as a warning sign.

A controlled trial of the efficacy and cost-effectiveness of vaccinating infants versus adolescents for the prevention of chronic carrier status in a vaccine-naive population would be ideal. However, there are few, if any, vaccine-naive populations in existence. Such a trial would likely take 10-20 years to produce results of any value. Currently, the evidence suggests that directing HBV vaccination resources toward uni- versal vaccination of infants would provide the best protection at the most relevant age.

The few jurisdictions that continue to offer universal immunization during adolescence rather than infancy should consider changing to a program for infants. Although vaccinating adolescents may offer some benefits, it is difficult to justify withholding proven, lasting protection from infants, given their high risk of chronic infections.

In jurisdictions that have already implemented a universal vaccination program for adolescents, the most comprehensive approach would be to implement a universal program for infants and to continue the adolescent program until the first cohort of infants reached the age at which they would have been offered the adolescent vaccine. Adolescent programs could be transitioned into catch-up programs. Simultaneous administration in several age groups could speed the process of ensuring that young children are protected.

The challenges of HBV immunization highlight the need for ongoing evaluation of all immunization programs. It is not possible to adequately answer these questions without the capacity to track epidemiologic data about vaccine-preventable diseases. Countries that have national immunization registries and surveillance for vaccine-preventable diseases will be better equipped to develop and evaluate immunization policy.

This article has been peer reviewed.

Competing interests: None declared.

Contributors: Christopher Mackie acquired, analyzed, interpreted the data and wrote the first draft of the manuscript. All of the authors contributed substantially to the conception and design of the manuscript, revised it critically for important intellectual content, and approved the final version submitted for publication.

Acknowledgements: We thank Gordon Tsoi, Alice Wong, Dr. Vladimir Gilca and Dr. Jun Wu for their assistance.

\section{REFERENCES}

1. Gilca V, Duval B, Boulianne N, et al. Impact of the Quebec school-based hepatitis B immunization program and potential benefit of the addition of an infant immunization program. Pediatr Infect Dis J 2006;25:372-4.

2. English P. Should universal hepatitis B immunization be introduced in the UK? Arch Dis Child 2006;91:286-9.

3. Beasley RP, Hwang LY, Lin CC, et al. Incidence of hepatitis B virus infections in preschool children in Taiwan. J Infect Dis 1982;146:198-204.

4. McMahon BJ, Alward WL, Hall DB, et al. Acute hepatitis B virus infection: relation of age to the clinical expression of disease and subsequent development of the carrier state. J Infect Dis 1985;151:599-603.

5. Tassopoulos NC, Papaevangelou GJ, Sjogren MH, et al. Natural history of acute hepatitis B surface antigen-positive hepatitis in Greek adults. Gastroenterology 1987;92:1844-50.

6. Nguyen VT, Law MG, Dore GJ. An enormous hepatitis B virus-related liver disease burden projected in Vietnam by 2025. Liver Int 2008;28:525-31.

7. Shepard CW, Finelli L, Fiore AE, et al. Epidemiology of hepatitis B and hepatitis B virus infection in United States children. Pediatr Infect Dis J 2005;24:755-60.

8. Qamer S, Shahab T, Alam S, et al. Age-specific prevalence of hepatitis B surface antigen in pediatric population of Aligarh, North India. Indian J Pediatr 2004;71:965-7.

9. McMahon BJ, Schoenberg S, Bulkow L, et al. Seroprevalence of hepatitis B viral markers in 52,000 Alaska Natives. Am J Epidemiol 1993;138:544-9.

10. Whittle H, Jaffar S, Wansbrough M, et al. Observational study of vaccine efficacy 14 years after trial of hepatitis B vaccination in Gambian children. BMJ 2002;325:569.

11. Dentinger CM, McMahon BJ, Butler JC, et al. Persistence of antibody to hepatitis $\mathrm{B}$ and protection from disease among Alaska Natives immunized at birth. Pediatr Infect Dis J 2005;24:786-92.

12. Liao S-S, Li R-C, Li H, et al. Long-term efficacy of plasma-derived hepatitis B vaccine: a 15-year follow-up study among Chinese children. Vaccine 1999;17:2661-6.

13. Yuen M-F, Lim W-L, Chan AO-O, et al. 18-year follow-up study of a prospective randomized trial of hepatitis B vaccinations without booster doses in children. Clin Gastroenterol Hepatol 2004;2:941-5. 
14. van der Sande MA, Waight PA, Mendy M, et al. Long-term protection against HBV chronic carriage of Gambian adolescents vaccinated in infancy and immune response in HBV booster trial in adolescence. PLOS ONE 2007;2:e753.

15. Expanded Programme on Immunization of the Department of Immunizations, Vaccines and Biologicals. WHO vaccine-preventable diseases: monitoring system, 2007 global summary. Geneva (Switzerland): World Health Organization; 2007. Available: http://whqlibdoc.who.int/hq/2007/WHO_IVB_2007_eng.pdf (accessed 2008 Dec 3).

16. Da Villa G, Peluso F, Picciotto L, et al. Persistence of anti-HBs in children vaccinated against viral hepatitis $B$ in the first year of life: follow-up at 5 and 10 years. Vaccine 1996;14:1503-5.

17. Da Villa G, Pelliccia MG, Peluso F, et al. Anti-HBs responses in children vaccinated with different schedules of either plasma-derived or HBV DNA recombinant vaccine. Res Virol 1997;148:109-14.

18. Poovorawan Y, Theamboonlers A, Hirsch P, et al. Persistence of antibodies to the surface antigen of the hepatitis B virus (anti-HBs) in children subjected to the Expanded Programme on Immunization (EPI), including hepatitis-B vaccine, in Thailand. Ann Trop Med Parasitol 2000;94:615-21.

19. Su F-H, Chen J-D, Cheng S-H, et al. Waning-off effect of serum hepatitis B surface antibody amongst Taiwanese university students: 18 years post-implementation of Taiwan's national hepatitis B vaccination programme. J Viral Hepatitis 2008;15:4-9.

20. Schreeder MT, Bender TR, McMahon BJ, et al. Prevalence of hepatitis B in selected Alaskan Eskimo villages. Am J Epidemiol 1983;118:543-9.

21. Barrett DH, Burks JM, McMahon B, et al. Epidemiology of hepatitis B in two Alaskan communities. Am J Epidemiol 1977;105:118-22.

22. Sung JL, Chen DS, Lai MY et al. Epidemiological study on hepatitis B virus infection in Taiwan. Chin J Gastroenterol 1984;1:1-9.

23. Wu JS, Chen $\mathrm{CH}$, Chiang $\mathrm{YH}$, et al. Hepatitis B virus infection in Taiwan with reference to anti-HBc versus HBsAg and anti-HBs. Taiwan Yi Xue Hui Za Zhi 1980; 79:760-7.

24. Lok AS, Lai CL, Wu PC, et al. Hepatitis B infection in Chinese families in Hong Kong. Am J Epidemiol 1987;126:492-9.

25. Coursaget P, Leboulleux D, Soumare M, et al. Twelve-year follow-up study of hepatitis B immunization of Senegalese infants. J Hepatol 1994;21:250-4.

26. Berlioz-Arthaud A, Perolat P, Buisson Y. 10 year assessment of infant hepatitis B vaccination program, in the Loyalty Islands (New Caledonia). Vaccine 2003;21:2737-42.

27. Tsatsralt-Od B, Takahashi M, Endo K, et al. Prevalence of hepatitis B, C, and Delta virus infections among children in mongolia: progress in childhood immunization. J Med Virol 2007;79:1064-74

28. Edstam JS, Dulmaa N, Nymadawa P, et al. Comparison of hepatitis B vaccine coverage and effectiveness among urban and rural Mongolian 2-year-olds. Prev Med 2002;34:207-14.

29. Davaalkham D, Ojima T, Wiersma S, et al. Administration of hepatitis B vaccine in winter as a significant predictor of the poor effectiveness of vaccination in rural Mongolia: evidence from a nationwide survey. J Epidemiol Community Health 2007;61:578-84

30. The World Health Organization. Progress towards global immunization goals 2007: summary presentation of key indicators. Geneva: The Organization; 2008. Available: www.who.int/immunization_monitoring/data/SlidesGlobalImmunization .pdf (accessed 2008 Dec 3).

31. Public Health Agency of Canada. Publicly funded immunization programs in canada: routine schedule for infants and children (including special programs and catch-up programs). Ottawa (ON): The Agency; 2007. Available: www.phac-aspc .gc.ca/im/ptimprog-progimpt/table-1-eng.php (accessed 2008 Dec 15).

32. Patrick DM, Bigham M, Ng H, et al. Elimination of acute hepatitis B among adolescents after one decade of an immunization program targeting Grade 6 students. Pediatr Infect Dis $J$ 2003;22:874-7.

33. Salleras L, Dominguez A, Bruguera M, et al. Dramatic decline in acute hepatitis B infection and disease incidence rates among adolescents and young people after 12 years of a mass hepatitis B vaccination programme of pre-adolescents in the schools of Catalonia (Spain). Vaccine 2005;23:2181-4.

34. BC Centre for Disease Control. 2007 British Columbia Annual Summary of Reportable Diseases. Vancouver (BC): The Centre; 2008, Available: www.bccdc.org /content.php?item $=33$ (accessed 2008 Dec 3).

35. Notifiable diseases online. Ottawa (ON): Centre for Infectious Disease Prevention and Control, Public Health Agency of Canada; 2004. Available: http://dsolsmed.phac-aspc.gc.ca/dsol-smed/ndis/m_ind_e.html\#maps (accessed 2008 Dec 3).

36. Rapport sur l'ensemble des maladies des dix dernières années, Province du Quebec. Québec (QC): Institut national de sante publique du Quebec; 2008. Available: www.dspq.qc.ca/MADO/asp/rapportPublic.asp?id=0\# (accessed 2008 Sept 18).

37. BC Stats. Immigration by Area of Last Permanent Residence, January to December, 2006. British Columbia: BC Stats; 2007. Available: www.bcstats.gov.bc.ca /DATA/pop/mig/imm06tla.pdf (accessed 2008 Dec 10).

38. Lee C, Gong Y, Brok J, et al. Effect of hepatitis B immunisation in newborn infants of mothers positive for hepatitis B surface antigen: systematic review and meta-analysis. BMJ 2006;332:328-36.

39. Statistics Canada. Births and birth rate, by province and territory. Ottawa $(\mathrm{ON})$ : Statistics Canada; 2008. Available: www40.statcan.gc.ca/101/cst01/demo04a-eng htm (accessed 2008 August 15).

40. West DJ, Calandra GB. Vaccine induced immunologic memory for hepatitis B surface antigen: implications for policy on booster vaccination. Vaccine 1996 14:1019-27.

41. European Consensus Group on Hepatitis B Immunity. Are booster immunisations needed for lifelong hepatitis B immunity? Lancet 2000;355:561-5.

42. FitzSimons D, François G, Hall A, et al. Long-term efficacy of hepatitis B vaccine, booster policy, and impact of hepatitis B virus mutants. Vaccine 2005;23:4158-66.

43. Van Damme P, Van Herck K. A review of the long-term protection after hepatitis A and B vaccination. Travel Med Infect Dis 2007;5:79-84

44. Erickson LJ, De Wals P, Farand L. An analytical framework for immunization programs in Canada. Vaccine 2005;23:2470-6.

45. Lu C-Y, Ni Y-H, Chiang B-L, et al. Humoral and cellular immune responses to hepatitis B vaccine booster 15-18 years after neonatal immunization. J Infect Dis 2008; 197:1419-26

46. Center for Disease Control and Prevention (CDC). Vaccines and immunizations, programs and tools: $\mathrm{CDC}$ vaccine price list [prices last reviewed/updated: $2008 \mathrm{Nov}$ 5]. Atlanta (GA): Centers for Disease Control and Prevention; 2008. Available: www.cdc.gov/vaccines/programs/vfc/cdc-vac-price-list.htm (accessed 2008 Nov 18).

47. Scheifele D. Universal childhood hepatitis B vaccination: infants vs. preadolescents, the Canadian perspective. Pediatr Infect Dis J 1998;17:S35-7.

Correspondence to: Dr. Christopher Mackie, 1 Hughson St. N, 4th floor, Hamilton ON L8P 2E5; fax 905 546-4075;

mackieca@mcmaster.ca 